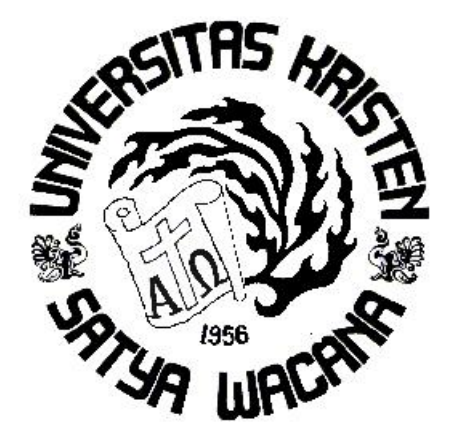

PERBEDAAN HASIL BELAJAR PKn SISWA KELAS V SD NEGERI 03 DAN 04 SURU KECAMATAN GEYER MENGGUNAKAN MODEL WORD SQUARE PADA SEMESTER II TAHUN PELAJARAN 2016/2017

\title{
TUGAS AKHIR
}

Untuk Memperoleh Gelar Sarjana Pendidikan pada Universitas Kristen Satya Wacana Salatiga

oleh

Nana Dwi Ervanasari

292013044

PROGRAM STUDI PENDIDIKAN GURU SEKOLAH DASAR

FAKULTAS KEGURUAN DAN ILMU PENDIDIKAN

UNIVERSITAS KRISTEN SATYA WACANA

SALATIGA 
PEapHSTAKAAN UNIVERSITAS UNIVERSTTAS KRASTEN SATYA WACANA

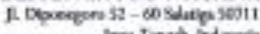

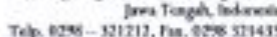

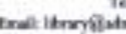

\section{PERNYATAAN TIDAK PLAGIAT}

Saya yang bertanda tangan đi bowah ini:

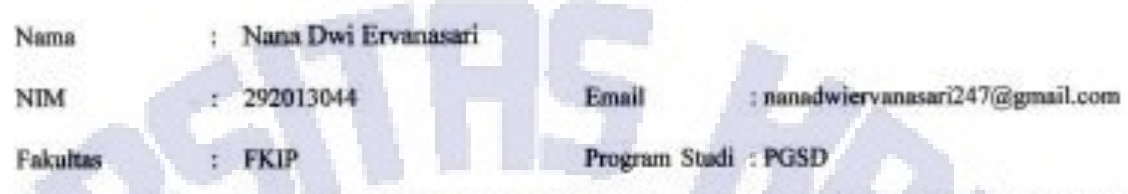

Judut tugas akhir : PERBEDAAN HASIL BEL.AJAR PKn SISWA KELAS V SD NEGERI 03 DAN 04 SURU KECAMATAN GEYER MENGGUNAKAN MODEL WORD SQUARE PADA SEMESTER II TAHUN PELAJARAN 2016/2017

Pembimbing

Dr. Y, Haris Nusarastriya, M.Si.

Dengan ini menyatakan bahwa:

1. Hasil karya yang saya serahkan ini adalah asli dan belam pernah diajukan untuk mendapatkan gelar kesarjanasn baik di Universitas Kristen Satya Wacana mavpun di institusi pendidikan lainnya.

2. Hasil karya saya ini bukan saduran/berjemahan melainkan merupakan gagasan, rumusan, dan hasil pelaksanaan penelitianimplenentasi saya sendiri, tanpa bantuan pihak lain, kecuali arahan pembimbing akademik dan narasumber penelitian.

3. Hasil karya saya ini merupakan hasil revisi terakhir setelah diujikan yang telah diketahui dan disetujui oleh pembimbing.

4. Dalam karya saya ini tidak terdapat karya atau pendapat yang telah ditulis atau dipublikasikan arang lain, kecuali yang digumekan sebagai acuan dalam naskah dengan menyebutkan sama pengarang dan dicantumkan dalam daftar pustaks.

Permyataan ini says bust dengan sesungguhmya. Apabila di kemudian hari terbukti ada penyimpangan dan ketidakbenanan dalam perayatasn ini maka saya bersedia menerima sanksi akademik berupa pencabutan gelar yang telah diperoleh karena karya saya tai, serta sanksi lain yang sesuai dengan ketentuan yang berlaku di Universitas Kristen Satya Wacana.

Salatiga, 11 Mei 2017

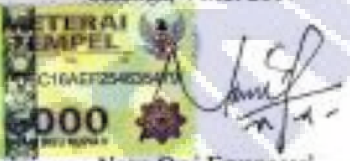

Nang Owi Ero:ans

F-1 IB-CG0 


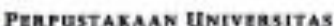
UNIVERCTTAS KHISTEN SATYA WACANA

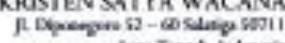

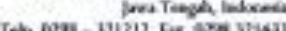
Tequ $\cos -13$

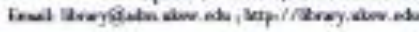

\section{PERNYATAAN PERSETUJUAN AKSES}

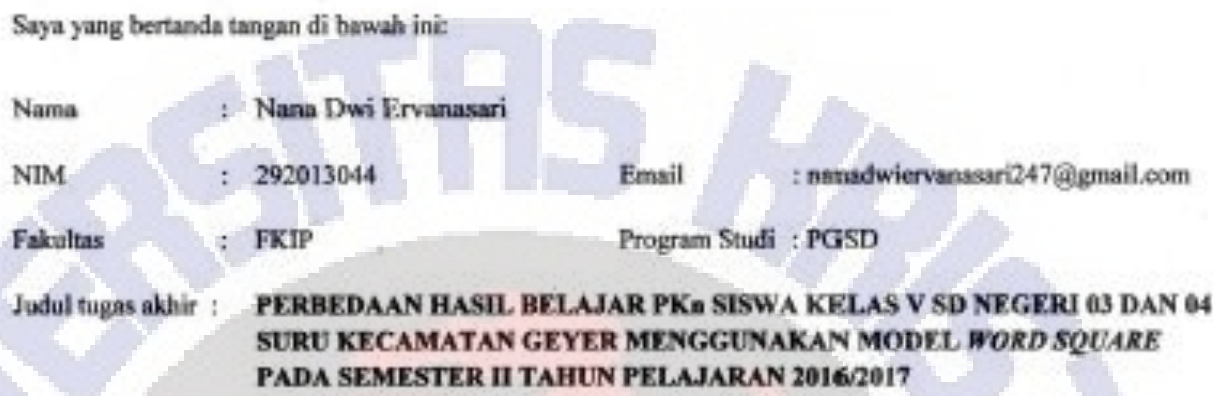

Judul tugas akhir : PERBEDAAN HASIL BELAJAR PKn SISWA KELAS V SD NE.GERI 03 DAN O4 SURU KECAMATAN GEYER MENGGUNAKAN MODEL WORD SQUARE PADA SEMESTER II TAHUN PELAJARAN 2016/2017

Dengan ini saya menyerahkan hak anw-eksthesif" kepada Perpustakaan Universitas - Universitas Kristen Satya Wacana untuk menyimpan, mengatur akses serta melakukan pengelolasn terhadap karya saya ini dengan mengacu pads ketentuan akses tugas akhir elektronik sebsesi berikut (beri tanda pada koesk yang sesuai):

a. Saya mengijinkan karya tersebut diunggah ke dalam aplikasi Repositori PerpustakaanUniversitas, deniatau portal GARUDA

Q b. Sayz tidak mengijinkan karya tersebut diungeh ke dalam aplikasi Repositori Perpustakaan Universitas, dandatau portal GARUDA**

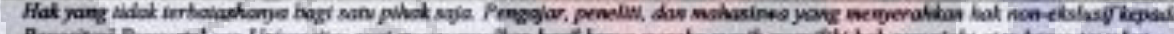

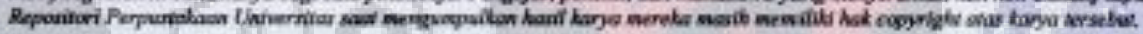

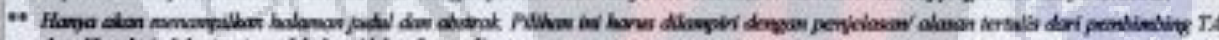

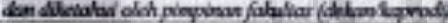

Demikian pernyataan ini saya buat dengan sebenamya.

Salatiga, 1OMei 2017
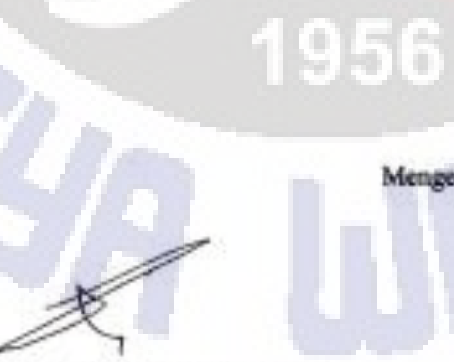

Dr. Y. Haris Nusarastriya, M.Si. Pembimbing

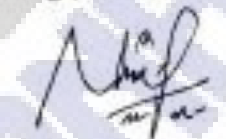

Nana Dwi Ervanasari

F.Lid-asi 


\section{LEMBAR PERSETUJUAN}

PERBEDAAN HASIL BELAJAR PKn SISWA KELAS V SD NEGERI 93 DAN O4 SURU KECAMATAN GEYER MENGGUNAKAN MODEL WORD SQUARE PADA SEMESTER II TAHUN

PELAJARAN 2016/2017

oleh

Nana Dwi Erwanasari

292013044

Laporan Tugas Akhir ini disetujui untuk ditinjau ulang

Salatiga, 7 April 2017

Dosen Pembimbing

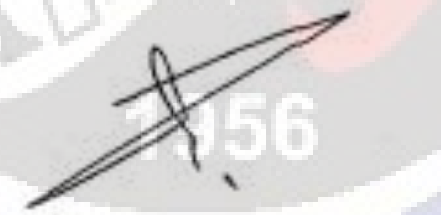

Dr. Y. Haris Nusarnastrlya, M.Si. 


\section{LEMBAR PENGESAHAN}

\section{PERBEDAAN HASIL BELAJAR PKn SISWA KELAS V SD NEGERI O3 DAN 04 SURU KECAMATAN GEYER MENGGUNAKAN MODEL WORD SQUARE PADA SEMESTER II TAHUN \\ PELAJARAN 2016/2017}

$$
\text { oleh }
$$

\section{Nana Dwi Ervanasari}

$$
292013044
$$

Laporan Tugas Akhir ini telah melalui proses peninjauan ulang pada tanggal 12 April 2017

Dr. Y. Haris Nusarastriya, M.Si.

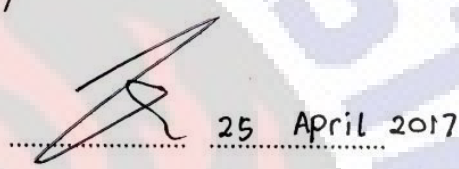

Dosen Pembimbing

Prof. Dr. Slameto, M.Pd.

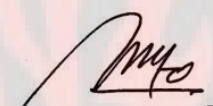
25 April 2017

Dosen Peninjau

$$
\text { Mengesahkan, }
$$

\section{ITfS R}

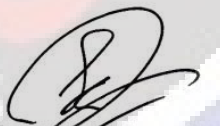

Dr. Yari Dwikurnaningsih, M..Pd. Stefanus C. Relmasira, S.Pd., MSEd.

U Kaprogdi PGSD 


\section{MOTTO}

"Orang-orang hebat di bidang apapun bukan baru bekerja karena mereka terinspirasi, namun mereka menjadi terinspirasi karena mereka lebih suka bekerja. Mereka tidak menyia-nyiakan waktu untuk menunggu inspirasi"

"Orang-orang yang sukses telah belajar membuat diri mereka

melakukan hal yang harus dikerjakan ketika hal itu memang harus diker jakan, entah mereka menyukainya atau tidak"

TIADA DOA YANG LEBIH INDAH SELAIN DOA AGAR TUGAS AKHIR INI CEPAT SELESAI 


\section{PERSEMBAHAN}

Tugas akhir ini aku persembahkan untuk:

1) Bapak dan Ibu tercinta yang selalu memberikan doa, semangat, motivasi serta dukungan baik berupa materi maupun non materi.

2) Kakakku tersayang

3) SD Negeri 03 Suru dan SD Negeri 04 Suru

\section{6}




\section{KATA PENGANTAR}

Puji syukur penulis panjatkan kehadirat Allah SWT atas rahmat, anugerah, dan karunia-Nya yang telah dilimpahkan sehingga tugas akhir yang berjudul "Perbedaan Hasil Belajar PKn Siswa Kelas V SD Negeri 03 dan 04 Suru Kecamatan Geyer Menggunakan Model Word Square pada Semester II Tahun Pelajaran 2016/2017" dapat terselesaikan dengan baik. Tugas akhir ini disusun dalam rangka memperoleh Gelar Sarjana Pendidikan pada Universitas Kristen Satya Wacana Salatiga.

Penulisan laporan penelitian ini untuk mengetahui perbedaan hasil belajar pada siswa kelas V antara SD Negeri 03 Suru dengan SD Negeri 04 Suru Kecamatan Geyer menggunakan model Word Square pada semester II tahun pelajaran 2016/2017.

Penulis menyadari bahwa tugas akhir ini tidak akan terwujud tanpa adanya bantuan dari pihak lain, sehingga dalam kesempatan ini penulis tidak lupa untuk mengucapkan terimakasih kepada:

1. Dr. Yari Dwi Kurnaningsih, M.Pd, selaku Dekan Fakultas Keguruan dan Ilmu Pendidikan Universitas Kristen Satya Wacana yang telah memberi fasilitasfasilitas yang menjunjung perkuliahan hingga selesainya studi penulis.

2. Stefanus C. Relmasira, S.Pd, MSEd, selaku Kaprogdi PGSD FKIP Universitas Kristen Satya Wacana yang telah memberikan kesempatan penulis dalam menyelesaikan studi.

3. Dr. Y. Haris Nusarastriya, M.Si, selaku dosen pembimbing tugas akhir yang telah meluangkan waktu, tenaga dan pikiran untuk memberikan bimbingan dan pengarahan kepada penulis sampai selesainya penulisan tugas akhir ini.

4. Prof. Dr. Slameto, M.Pd, selaku reviewer tugas akhir yang telah memberikan masukan dan perbaikan sampai terselesainya tugas akhir ini.

5. Indri Anugraheni, S.Pd, M.Pd, selaku Wali Studi RS13B program studi PGSD FKIP UKSW. Para dosen Program Studi PGSD FKIP UKSW yang telah memberikan bekal dan ilmu pengetahuan yang sangat bermanfaat bagi penulis hingga penulis dapat menyelesaikan studi. 
6. Kepala Sekolah dan Guru-Guru di SD N 03 Suru dan SD N 04 Suru yang telah memberikan ijin dan membantu jalannya penelitian.

7. Siswa-siswi kelas V di SD N 03 Suru dan SD N 04 Suru yang telah bersedia membantu dalam pelaksanaan penelitian ini.

8. Kedua orang tua dan keluarga yang telah memberikan dukungan dan doanya sehingga penulis dapat menyelesaikan studi di program studi S1 PGSD FKIP UKSW.

9. Teman-teman S1 PGSD FKIP UKSW angkatan 2013 khususnya RS13B yang selama ini telah berjuang bersama menyelesaikan tugas akhir.

10.Semua pihak yang telah membantu kelancaran dalam penyusunan laporan ini yang tidak dapat penulis sebutkan satu persatu.

Semoga tugas akhir ini bermanfaat bagi banyak pihak, khususnya dunia pendidikan dan umumnya bagi pembaca.

Salatiga, 3 April 2017

Penulis 


\begin{abstract}
ABSTRAK
Ervanasari, Nana Dwi. 2017. Perbedaan Hasil Belajar PKn Siswa Kelas V SD Negeri 03 Dan 04 Suru Kecamatan Geyer Menggunakan Model Word Square Pada Semester II Tahun Pelajaran 2016/2017. Program Studi S1 PGSD FKIP Universitas Kristen Satya Wacana Salatiga. Pembimbing Dr. Y. Haris Nusarastriya, M. Si.
\end{abstract}

\title{
Kata Kunci: Model Pembelajaran Word Square, Hasil Belajar PKn.
}

Pendidikan Kewarganegaraan adalah salah satu mata pelajaran yang mendidik generasi muda untuk menjadi warga negara yang kritis, aktif, demokratis serta sadar akan hak dan kewajibannya dalam kehidupan bermasyarakat. Pembelajaran adalah suatu proses dimana terjadi hubungan antara guru atau pendidik dengan murid dan sumber belajar yang saling bertukar informasi. Guru harus memperhatikan beberapa hal dalam melaksanakan pembelajaran. Salah satunya adalah pemilihan model pembelajaran yang tepat dengan mata pelajaran PKn yaitu model pembelajaran Word Square. Penelitian ini bertujuan untuk mengetahui perbedaan hasil belajar PKn siswa kelas V antara SD Negeri 03 Suru dengan SD Negeri 04 Suru yang sama-sama menggunakan model Word Square. Jenis penelitian yang digunakan adalah penelitian eksperimen semu (quasi eksperimental research) dengan desain Nonequivalent Control Group Design. Subjek penelitian yaitu siswa kelas V SD Negeri 03 Suru sebagai kelompok eksperimen A dan siswa kelas V SD Negeri 04 Suru sebagai kelompok eksperimen B. Teknik pengumpulan data dalam penelitian adalah observasi dan tes, sedangkan untuk analisis data menggunakan analisis deskriptif, uji prasyarat (normalitas, homogenitas, dan uji t) menggunakan bantuan SPSS 20. Hasil penelitian setelah dilakukan analisa data hasil uji $t$ menunjukkan nilai $t$ hitung lebih kecil dari t tabel $(0,872<2,018)$, sedangkan untuk nilai signifikansinya lebih besar dari 0,05 (0,388>0,05). Dengan demikian, dapat disimpulkan bahwa tidak ada perbedaan hasil belajar PKn antara siswa kelas V SD Negeri 03 dengan siswa kelas V SD Negeri 04 Suru yang mendapat perlakuan sama yaitu menggunakan model Word Square. 


\section{DAFTAR ISI}

HALAMAN JUDUL....................................................................... i

LEMBAR PERNYATAAN TIDAK PLAGIAT …................................... ii

LEMBAR PERSETUJUAN AKSES ..................................................... iii

LEMBAR PERSETUJUAN ........................................................... iv

LEMBAR PENGESAHAN …….................................................... v

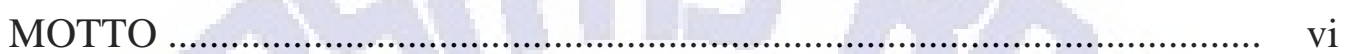

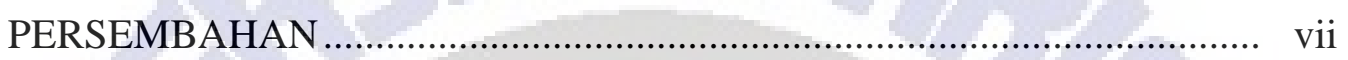

KATA PENGANTAR ............................................................. viii

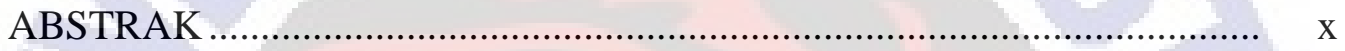

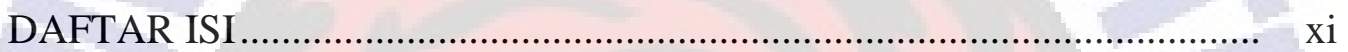

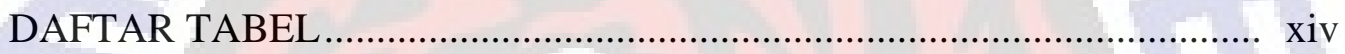

DAFTAR GAMBAR …......................................................... x

DAFTAR LAMPIRAN ……........................................................... xvii

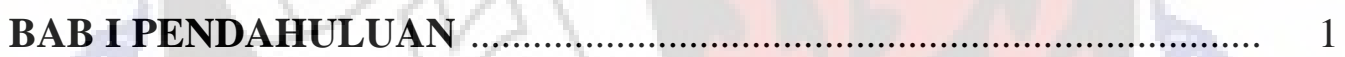

1.1 Latar Belakang Masalah ............................................................... 1

1.2 Identifikasi Masalah ...................................................................... 4

1.3 Rumusan Masalah .............................................................................. 4

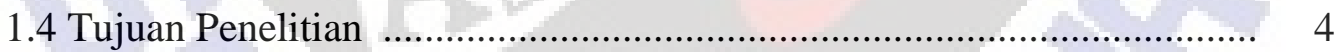

1.5 Manfaat Penelitian _..................................................................... 5

1.5.1 Manfaat Teoritis ................................................................... 5

1.5.2 Manfaat Praktis ..................................................................... 5

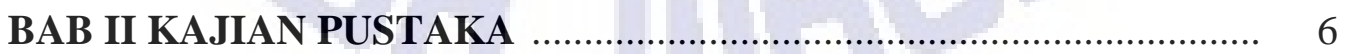

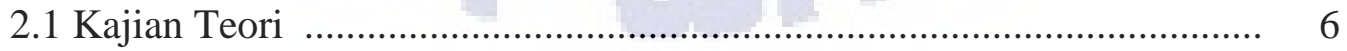

2.1.1 Hakikat PKn .............................................................................. 6

2.1.2 Pembelajaran PKn di SD ................................................................ 7

2.1.3 Model Pembelajaran Word Square ................................................ 10

2.1.4 Hasil Belajar ........................................................................ 12

2.1.4.1 Faktor-faktor yang Mempengaruhi Hasil Belajar .......................... 13

2.1.5 Implementasi Pembelajaran Kooperatif Tipe Word Square ................ 15 
2.1.6 Hubungan antara Pembelajaran Word Square dengan

Hasil Belajar PKn ................................................................. 18

2.2 Kajian Hasil-hasil Penelitian yang Relevan ......................................... 19

2.3 Kerangka Berpikir ..................................................................... 21

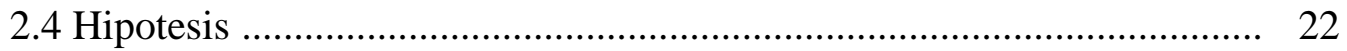

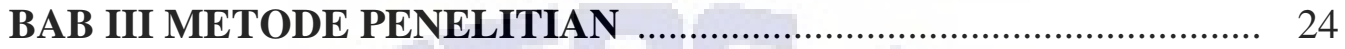

3.1 Jenis, Desain, dan Lokasi Penelitian .................................................. 24

3.1.1 Jenis Penelitian ........................................................................ 24

3.1.2 Desain Penelitian ................................................................... 24

3.1.3 Lokasi dan Waktu Penelitian .......................................................... 25

3.2 Variabel Penelitian dan Definisi Operasional f.................................... 25

3.2.1 Variabel Penelitian ................................................................... 26

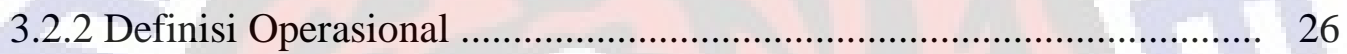

3.3 Teknik dan Instrumen Pengumpulan Data ........................................ 26

3.3.1 Teknik Pengumpulan Data .......................................................... 26

3.3.2 Instrumen Pengumpulan Data ................................................... 27

3.4 Validitas dan Reliabilitas Instrumen ............................................... 31

3.4.1 Uji Validitas Instrumen ......................................................... 31

3.4.2 Uji Reliabilitas Instrumen ...................................................... 32

3.4.3 Uji Taraf Kesukaran Soal _...................................................... 33

3.5 Teknik Analisis Data................................................................. 35

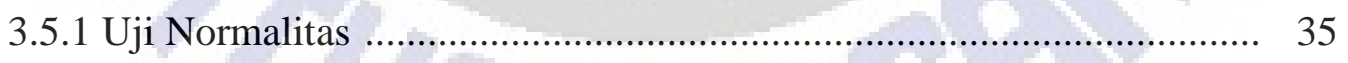

3.5.2 Uji Homogenitas ............................................................... 37

3.5.3 Uji Hipotesis ...................................................................... 38

BAB IV HASIL PENELITIAN DAN PEMBAHASAN ....................... 39

4.1 Gambaran Umum Subjek Penelitian ................................................... 39

4.2 Hasil Pelaksanaan Penelitian ................................................................ 40

4.2.1 Pelaksanaan Pembelajaran Kelas Eksperimen A .............................. 42

4.2.2 Pelaksanaan Pembelajaran Kelas Eksperimen B .............................. 45

4.3 Data Hasil Penelitian ......................................................................... 49

4.3.1 Deskripsi Data ........................................................................... 49 


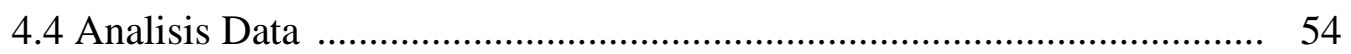

4.4.1 Analisis Deskriptif Data ........................................................... 54

4.4.2 Uji Prasyarat ............................................................................ 55

4.4.3 Analisis Uji Hipotesis ................................................................... 59

4.5 Pembahasan Hasil Penelitian .................................................................... 60

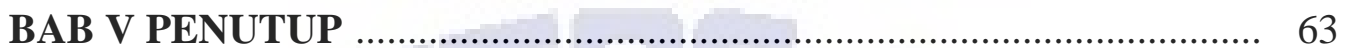

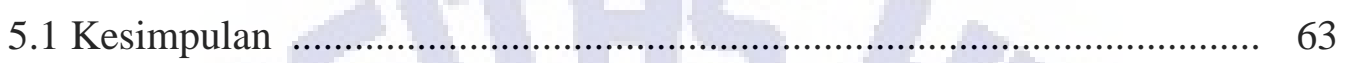

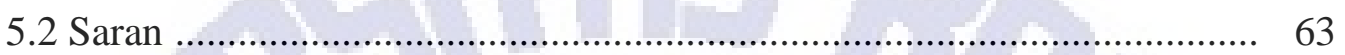

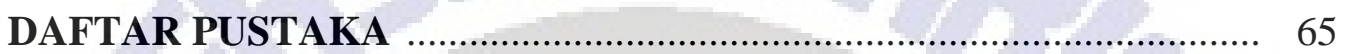

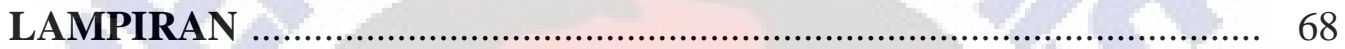




\section{DAFTAR TABEL}

Tabel 1. Pemetaan Ruang Lingkup dan Materi Belajar PKn SD .................. 9

Tabel 2. Sintak Pembelajaran Kooperatif Tipe Word Square ........................ 11

Tabel 3. Desain Penelitian Nonequivalent Control Group Design ................. 24

Tabel 4. Kisi-kisi Lembar Observasi Guru Model Word Square Kelompok Eksperimen A dan Kelompok Eksperimen B

Tabel 5. Kisi-kisi Lembar Observasi Respon Siswa dalam Penerapan

Model Word Square Kelompok Eksperimen A dan Kelompok

Eksperimen B

Tabel 6. Kisi-kisi Soal Pretest dan Posttest Kelompok Eksperimen A dan

Kelompok Eksperimen B

Tabel 7. Kevalidan dan Ketidakvalidan Soal Pretest dan Posttest .

Tabel 8. Hasil Uji Reliabilitas Instrumen Pretest dan Posttest ...................... 33

Tabel 9. Rentang Nilai Tingkat Kesukaran ................................................. 34

Tabel 10. Hasil Tingkat Kesukaran Soal Pretest dan Posttest ....................... 34

Tabel 11. Hasil Uji Normalitas Instrumen Pretest Kelas V SD N 03 Suru (Kelompok Eksperimen A) dan Kelas V SD N 04 Suru (Kelompok Eksperimen B) Semester II Tahun Pelajaran $2016 / 2017$ 35

Tabel 12. Hasil Uji Homogenitas Pretest Kelas V SD N 03 Suru (Kelompok Eksperimen A) dan Kelas V SD N 04 Suru (Kelompok Eksperimen B) Semester II Tahun Pelajaran 2016/2017 38

Tabel 13. Subjek Penelitian 39

Tabel 14. Kegiatan Pelaksanaan Penelitian Kelompok Eksperimen A dan Kelompok Eksperimen B Tahun Pelajaran 2016/2017

Tabel 15. Hasil Observasi Pelaksanaan Model Pembelajaran Word Square SD Negeri 03 Suru Terhadap Kelompok Eksperimen A Tahun Pelajaran 2016/2017 44

Tabel 16. Hasil Observasi Respon siswa dalam Penerapan Model Word 
Square SD Negeri 03 Suru Terhadap Kelompok Eksperimen A Tahun Pelajaran 2016/2017

Tabel 17. Hasil Observasi Pelaksanaan Model Pembelajaran Word Square SD Negeri 04 Suru Terhadap Kelompok Eksperimen B Tahun Pelajaran 2016/2017 48

Tabel 18. Hasil Observasi Respon Siswa dalam Penerapan Model Word Square SD Negeri 04 Suru Terhadap Kelompok Eksperimen B Tahun Pelajaran 2016/2017

Tabel 19. Distribusi Frekuensi Skor Hasil Belajar PKn Kelas V SD Negeri 03 Suru Kelompok Eksperimen A Tahun Pelajaran $2016 / 2017$

Tabel 20. Distribusi Frekuensi Skor Hasil Belajar PKn Kelas V SD Negeri 04 Suru Kelompok Eksperimen B Tahun Pelajaran 2016/2017 ...... 53

Tabel 21. Analisis Deskriptif Skor Hasil Belajar PKn Kelompok Eksperimen A dan Kelompok Eksperimen B Tahun Pelajaran $2016 / 2017$

Tabel 22. Hasil Uji Normalitas Hasil Belajar PKn Kelompok Eksperimen A dan Kelompok Eksperimen B Tahun Pelajaran 2016/2017 56

Tabel 23. Hasil Uji Homogenitas Skor Hasil Belajar PKn Kelompok Eksperimen A dan Kelompok Eksperimen B Tahun Pelajaran $2016 / 2017$ 58

Tabel 24. Rata-rata Skor Hasil Belajar PKn Kelompok Eksperimen A dan Kelompok Eksperimen B Tahun Pelajaran 2016/2017 58

Tabel 25. Hasil Uji t Skor Hasil Belajar PKn Kelompok Eksperimen A dan Kelompok Eksperimen B Tahun Pelajaran 2016/2017 59 


\section{DAFTAR GAMBAR}

Gambar 1. Grafik Uji Normalitas Pretest Kelompok Eksperimen A 36

Gambar 2. Grafik Uji Normalitas Pretest Kelompok Eksperimen B

Gambar 3. Grafik Distribusi Frekuensi Skor Hasil Belajar PKn SD N 03 Suru Tahun Pelajaran 2016/2017

Gambar 4. Grafik Distribusi Frekuensi Skor Hasil Belajar PKn SD N 04 Suru Tahun Pelajaran 2016/2017

Gambar 5. Grafik Uji Normalitas Skor Hasil Belajar PKn Kelompok

Eksperimen A

Gambar 6. Grafik Uji Normalitas Skor Hasil Belajar PKn Kelompok

Eksperimen B

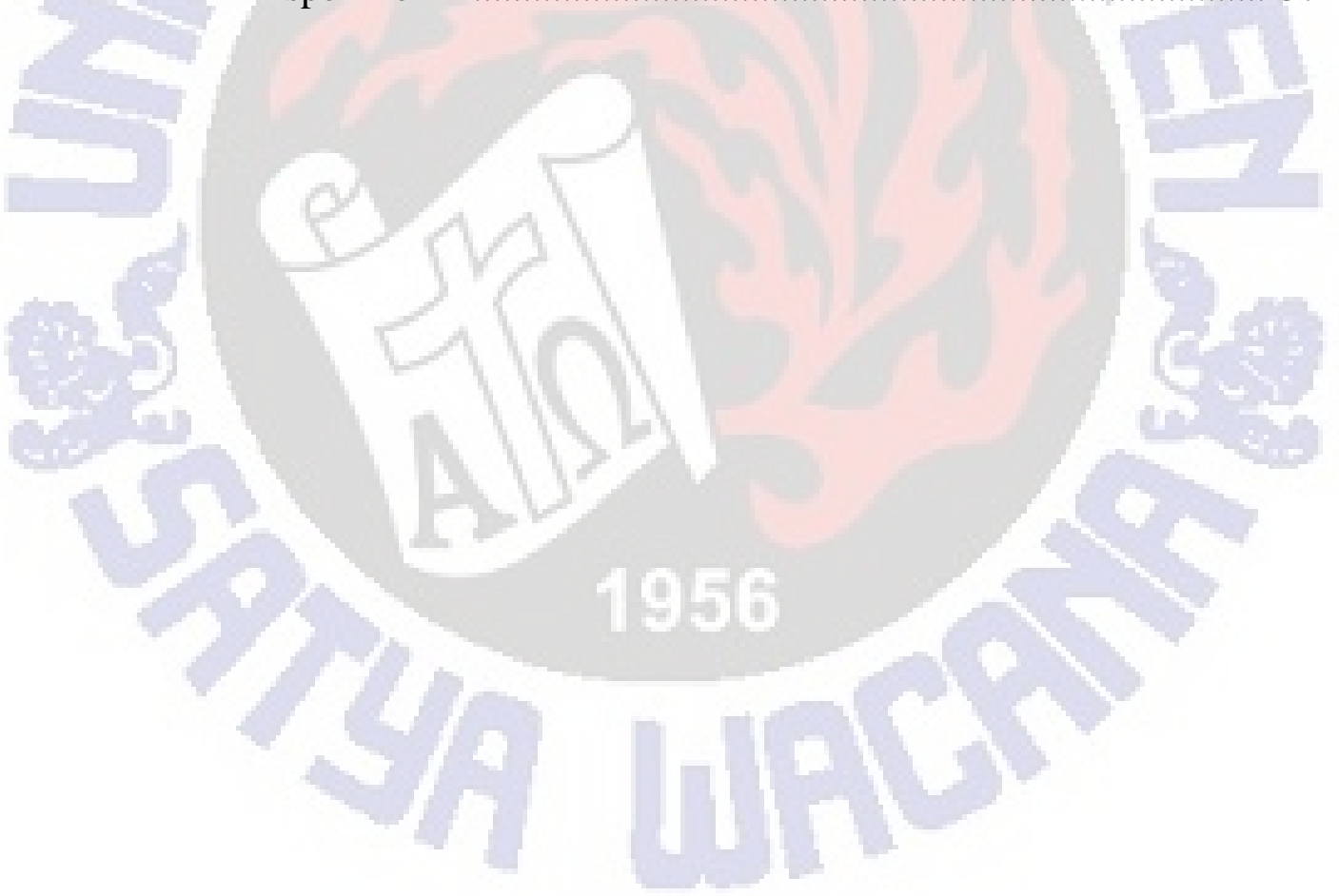




\section{DAFTAR LAMPIRAN}

Lampiran 1. Surat Ijin Penelitian

Lampiran 2. Instrumen Tes Hasil Belajar PKn Sebelum Validasi Materi

Organisasi

Lampiran 3. Kunci Jawaban Instrumen Tes Hasil Belajar PKn Sebelum

Validasi

Lampiran 4. Hasil Uji Validitas Instrumen

Lampiran 5. Instrumen Tes Hasil Belajar PKn Setelah Validasi

(Uji Kesetaraan)

Lampiran 6. Kunci Jawaban Instrumen Hasil Belajar PKn

(Uji Kesetaraan) Setelah Validasi

Lampiran 7. Data Hasil Belajar PKn (Uji Kesetaraan) Kelompok

Eksperimen A dan Kelompok Eksperimen B

Lampiran 8. Instrumen Tes Hasil Belajar PKn (Posttest)

Lampiran 9. Kunci Jawaban Instrumen Tes Hasil Belajar PKn

(Posttest)

Lampiran 10. Data Hasil Belajar PKn Kelompok Eksperimen A dan

Kelompok Eksperimen B

Lampiran 11. Rencana Pelaksanaan Pembelajaran (RPP) Kelompok

Eksperimen A dan Kelompok Eksperimen B

Lampiran 12. Hasil Observasi Kelompok Eksperimen A dan Kelompok

Eksperimen B

Lampiran 13. Dokumentasi Penelitian Kelompok Eksperimen A dan

Kelompok Eksperimen B

Lampiran 14. Hasil Plagiarism Checking 